\title{
Why don't patients do their exercises? Understanding non-compliance with physiotherapy in patients with osteoarthritis of the knee
}

\author{
R Campbell, M Evans, M Tucker, B Quilty, P Dieppe, J L Donovan
}

\begin{abstract}
Study objectives-To understand reasons for compliance and non-compliance with a home based exercise regimen by patients with osteoarthritis of the knee.

Design-A qualitative study, nested within a randomised controlled trial, examining the effectiveness of physiotherapy in reducing pain and increasing mobility in knee osteoarthritis. In the intervention arm, participants undertook a series of simple exercises and repositioning of the kneecap using tape. In depth interviews were conducted with a subset of participants in the intervention arm using open ended questions, guided by a topic schedule, to encourage patients to describe their experiences and reflect on why they did or did not comply with the physiotherapy. Interviews were audiotaped, fully transcribed and analysed thematically according to the method of constant comparison. A model explaining factors influencing compliance was developed.
\end{abstract}

Setting-Patients were interviewed at home. The study was nested within a pragmatic randomised controlled trial.

Participants-Twenty participants in the intervention arm of the randomised trial were interviewed three months after they had completed the physiotherapy programme. Eight were interviewed again one year later.

Department of Social Medicine, University of Bristol, Whiteladies Road, Bristol

BS8 4SH, UK

R Campbell

M Evans

J L Donovan

Department of Rheumatology, University of Bristol M Tucker B Quilty

MRC Health Services Research

Collaboration,

University of Bristol

P Dieppe

Correspondence: Dr

Campbell

(rona.campbell@bris.ac.uk)

Accepted for publication 22 September 2000 clude qualitative research within trials whenever levels of compliance may have an impact on the effectiveness of the intervention.

(f Epidemiol Community Health 2001;55:132-138)

Research has consistently shown that up to half of all patients do not follow recommended drug regimens. ${ }^{1-7}$ This non-compliance has been associated with substantial costs, including avoidable morbidity, increased hospital and nursing home admissions, and prolonged hospital stays. ${ }^{36}$ Within randomised controlled trials (RCTs), non-compliance can lead to incorrect conclusions about therapeutic efficacy. ${ }^{8} 9$ Issues of non-compliance have been relatively neglected for physical therapies that are the recommended first line therapy for many chronic musculoskeletal disorders including osteoarthritis of the knee. ${ }^{1011}$ The aim of physiotherapy is to improve muscle strength and joint mobility, often requiring considerable commitment by patients over long periods of time. There is very little robust evidence concerning the effectiveness of physiotherapy, ${ }^{12}{ }^{13}$ and little is known about compliance with physiotherapy, except that similar proportions seem to be non-compliant as with drug therapies. ${ }^{14-18}$

Non-compliance is traditionally defined as a failure by patients to follow advice. ${ }^{19} 20$ Attempts have been made to reduce the proportion of non-compliers, ${ }^{3421}$ but with little apparent effect on levels of compliance. More recent interest has focused on patient perspectives of medication advice. Sociological research suggests patients make reasoned and rational decisions about medication taking, depending on their own beliefs about drug therapies, personal experiences and the information they have available. ${ }^{72-25}$ In this study, we explored compliance with physiotherapy from the patient's perspective, using qualitative research methods to find out whether levels of, and reasons for, non-compliance with physical therapies are similar to those for drug therapies.

This study was nested within an RCT designed to test the effectiveness of a complex physiotherapy intervention in reducing knee pain and mobility restriction associated with osteoarthritis of the knee. From a sample of people identified in the community with symptomatic patellofemoral osteoarthritis of the knee, 87 people were recruited to the trial, of 
whom 43 were randomised to the treatment arm. The trial results showed that five months after the start of treatment there was a small decrease in pain and a significant increase in the strength of the quadriceps muscle of the index knee. After one year, however, there were no significant differences in the outcome measures, most of which had returned to pre-treatment levels. ${ }^{26}$

\section{Methods}

THE PHYSIOTHERAPY TRIAL

The physiotherapy intervention in the randomised trial comprised home based exercises to strengthen the vastus medialis component of the quadriceps muscle, medial taping of the patella, ${ }^{27}$ advice and information leaflets. Those randomised to the intervention arm received nine half hour treatment sessions over an eight week period and were encouraged to continue with the exercises and taping at home; those in the control group received only general advice about weight reduction and exercise at a single baseline visit. At the end of the physiotherapy programme, the therapist (MT) recorded whether she thought patients had complied fully or partially.

\section{QUALITATIVE RESEARCH}

Informants for the qualitative study were then selected by RC from the list of patients in the intervention arm to obtain a "maximum variation" sample ${ }^{28}$ including a balance of full and partial compliers (according to MT), men and women and older and younger people. In total, 20 informants were interviewed in depth after the completion of the physiotherapy programme but before the five month trial follow up appointment. This timing was chosen so that the qualitative research would not interfere unduly with the conduct of the trial. To explore issues around longer term compliance, follow up interviews were conducted after the end of the trial period with eight participants identified by RC from their first interview transcripts to have been mostly compliant with the exercise programme.

All interviews were conducted in informants' homes by ME who was kept blind to the physiotherapist's assessment of level of compliance. Interviews lasted between 30 and 90 minutes and were guided by a checklist of topics to ensure that similar issues were always explored, including history and severity of knee symptoms, recall of and compliance with physiotherapy programme, and previous experiences of treatments, but were also open ended to allow other issues of importance to participants to emerge and be considered. ${ }^{29} 30$ Interviews were audio taped, transcribed verbatim, and checked by $\mathrm{ME}$ and RC for accuracy. Interviews and preliminary analyses were undertaken sequentially to allow emerging analyses to influence subsequent interviews. Interview transcripts were read repeatedly and emergent themes used to code sections of the text, which were copied to new word processing files. Codes were applied to subsequent interviews and further codes added as new themes emerged, according to the constant compara-
Table 1 Characteristics of informants

\begin{tabular}{llll}
\hline & \multicolumn{2}{l}{ Sex } & \\
\cline { 2 - 3 } Age group & Male & Female & Total \\
\hline $45-59$ & & 6 & 6 \\
$60-69$ & 1 & 4 & 5 \\
70 and over & 5 & 4 & 9 \\
Total & 6 & 14 & 20 \\
\hline
\end{tabular}

tive method. ${ }^{31}$ These word processed files were used alongside the interview transcripts to produce descriptive accounts of the data and a model was developed inductively by RC to display and explain relations between major themes. ${ }^{32}$ Data analysis was conducted largely by RC in collaboration with ME, JD and PD. These researchers met to check the plausibility of the data interpretation and to agree on the meaning of the thematic categories to be used to index interview transcripts. The main themes to emerge from the data are presented below with quotations, selected because they were typical of the observations or insights which informants gave.

\section{Results}

Twenty trial participants were selected for interview: 14 were women, six men; and six were under 60 years, five 60-69 years and nine 70 years or over (see table 1). According to MT's assessment, eight informants were considered to be fully compliant and 12 partially compliant at the end of the physiotherapy programme. Table 2 shows the assessment of the level of compliance at each stage. Eight informants who, after analysis of their first interviews, were considered by RC to be most likely to be compliant longer term, were interviewed again one year later. Levels of compliance in the informants interviewed again are also shown in table 2 .

There was a relatively high degree of concordance between MT's assessment of initial compliance and the levels of compliance reported at interview, and in the five cases where there was discordance, interview data suggested that patients were more compliant than the physiotherapist thought. Overall, most informants understood and acknowledged, as they were instructed by the physiotherapist, that they should do the exercises often and regularly, but many undertook only a limited programme of exercise. On the whole, informants continued to undertake exercises that they found easiest or from which they perceived they would derive the most benefit:

Florence: "I wouldn't say that I managed to do all of them every day, not all the ones she gave us but, I almost certainly did some of them every day, you know."

Stanley: "Well, there was a pamphlet which we had and they [the frequency with which the exercises were to be done] varied according to each exercise. (ME: Oh I see) some ten, times, some only once-which I tried to do, and the ones obviously I felt was more beneficial or useful, I done perhaps a little more than the one .... yes, I did more of those than the ones which I think didn't do me any good anyway'.

Two distinct phases of reported compliance were apparent: initially, when informants were 
Table 2 Assessment of the level of compliance with the home exercises at each stage

\begin{tabular}{|c|c|c|c|c|}
\hline \multirow[b]{2}{*}{ Name } & \multirow[b]{2}{*}{$\begin{array}{l}\text { Physiotherapist's assessment } \\
\text { of compliance }\end{array}$} & \multicolumn{3}{|c|}{ Compliance reported at interview } \\
\hline & & $\begin{array}{l}\text { First interview } \\
\text { Initial }\end{array}$ & Continued & $\begin{array}{l}\text { Second interview } \\
\text { Long term }\end{array}$ \\
\hline June & Compliant & Compliant & Compliant & Compliant \\
\hline Pauline & Partially compliant & Compliant & Compliant & Compliant \\
\hline Alan & Partially compliant & Compliant & Compliant & Compliant \\
\hline Bridie & Compliant & Compliant & Compliant & Compliant \\
\hline Ann & Compliant & Compliant & Compliant & Compliant \\
\hline Elizabeth & Compliant & Compliant & Compliant & Partially compliant \\
\hline Florence & Partially compliant & Compliant & Compliant & Partially compliant \\
\hline Margo & Partially compliant & Compliant & Equivocal & Non-compliant \\
\hline Prue & Compliant & Compliant & Partially compliant & Unavailable \\
\hline Stanley & Compliant & Compliant & Non-compliant & \\
\hline Graham & Compliant & Compliant & Non-compliant & \\
\hline Arthur & Compliant & Compliant & Non-compliant & \\
\hline Hilary & Partially compliant & Compliant & Non-compliant & \\
\hline $\mathrm{Vi}$ & Partially compliant & Partially compliant & Non-compliant & \\
\hline Kenneth & Partially compliant & Partially complaint & Non-compliant & \\
\hline Hilda & Partially compliant & Partially compliant & Non-compliant & \\
\hline Geoffrey & Partially compliant & Partially compliant & Non-compliant & \\
\hline Eileen & Partially compliant & Partially compliant & Non-compliant & \\
\hline Ethel & Partially compliant & Partially compliant & Non-compliant & \\
\hline Beryl & Partially complaint & Partially compliant & Non-compliant & \\
\hline
\end{tabular}

still attending physiotherapy sessions; and later, when a number of factors combined to determine continued and long term compliance (or non-compliance). These two stages will be explored in turn, below.

INITIAL COMPLIANCE

The complex reciprocity that surrounds the relationship between therapist and patient and the obligation patients felt towards the physiotherapist, particularly the desire not to let her down, were important reasons for high levels of initial compliance:

Geoffrey: "Well I felt because [physiotherapist] took the trouble of explaining it all to me I couldn't turn around and say, "well blow it, why bother sort of thing? you know?" And when I first turned round and said that I would do it, I felt well alright I wasn't obligated to do it but I felt let's do my bit towards it, you know. I didn't want her to simply think that she was wasting her time."

This sense of reciprocity and obligation also extended to the researchers undertaking the trial:

Kenneth: "I'm prepared to pile in and help out sort of thing, if that's what you want 'cause it helps both ways . ........ think it was worthwhile and if anything has come out in the form of knowledge or expertise, call it what you will, for any of the people I have seen [the physiotherapist and the researcher running the trial] then fine, I'm all for it."

A collectivist or altruistic ethic was also evident at this early stage:

Graham: "I felt that I was contributing in some ways to research which would probably benefit other people, and that really was why I went ahead with it ... I anticipated some benefit for myself, but I thought well, this is great if this is going on, then I am participating in something really worthwhile."

Alan: I went along, my own attitude in the back of my mind was, I don't think it's going to do me a lot of good, but the way I look at it was, sometime in the future, what they learn from here, might possibly benefit somebody else ... So I did it more for the sake of the research than anything else"
A dislike of taking prescription drugs and a positive view or experience of physiotherapy also provided an initial motivation to comply: Prue: "I am not a one for taking a lot of tablets. I get a bit dubious, you know, so I just learnt to live with it for a bit and then I had the chance of [the trial]."

June: "I'm a great believer in physiotherapy anyway I think. I don't agree with drugs quite as much as, I think, if you can have it naturally."

CONTINUED COMPLIANCE

Although everyone reported doing exercises at home to some extent while attending the physiotherapy sessions, only seven (out of 20) were consistently exercising three months later, and only five of these eight months later. The reasoning behind continued compliance or non-compliance was more complex than in the initial stages and revolved around the interplay between the condition (symptoms of pain and stiffness in the knee), the perceived effectiveness of the intervention (exercises and taping) and "motivation" (the reasoning behind compliance or non-compliance) (see model in fig 1). The engine of the model was "motivation to comply", and this was associated with the following major themes:

\section{(a) Attitudes towards exercise}

While a positive disposition towards exercise could increase motivation, more important was the willingness and ability to accommodate the exercises into everyday life:

Alan: "It wasn't so much at home I am able to do it, it's more at work .... Perhaps not as often as I would really like to, but I can do it quite freely then, because I'm totally on my own." Those who ceased exercising often cited conflict with regular routines to explain why continuing with exercises was not possible:

Kenneth: "So many things happening ... The boys used to come in from school or work .....people come and see [wife] and ugh ... I'm out twice at least a week to band practice and I have two engagements as well."

Eileen: "Weekends I try to do [the exercises] but I am very busy on the weekend really it is the only chance I get to do sort of any cleaning. 


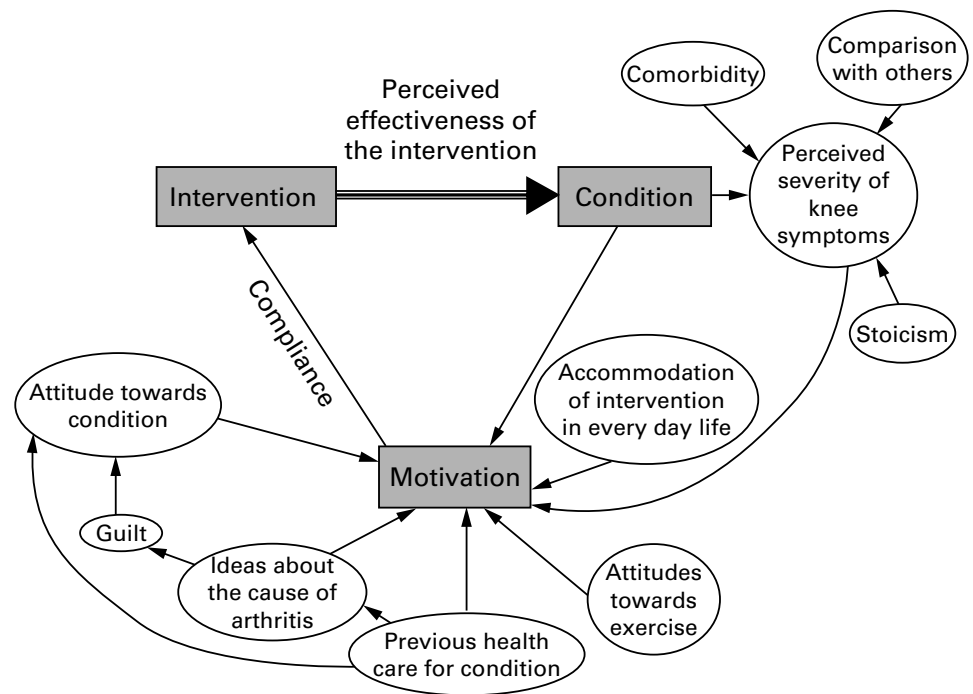

Figure 1 Model of continued compliance.

Then my family usually come up in the afternoon, my sister and her husband, because on the way to Mum's they always come in. Sunday's I have Mum on Sunday see, then I have her two sisters because they are older."

By giving these explanations Kenneth and Eileen could have been trying to portray themselves in a favourable light by indicating that their non-compliance was due to family commitments and obligations. Nevertheless, later in their interviews both went on to admit some personal responsibility for their lack of compliance. Kenneth, for example, indicated that non-compliance resulted from a combination of a busy life and a reduced commitment to the physiotherapy:

Kenneth: "It's just excuses when it comes down to basics. I mean you know you could get up in the morning and do it between 6 or 7 or something like that."

Eileen explained how difficult it was to continue the exercises programme since she stopped seeing the physiotherapist.

ME: "So would you say that some weeks you do them [the exercises] two or three times?" Eileen: "Some weeks I can't . ..."

ME: "Sometimes you can't make it at all?" Eileen: Yeah. Latterly. I think this is my own fault. I mean when I was going [to see the physiotherapist $]$ every week you make yourself sort of do it don't you . . ...I must admit I am not so good now I am not going"

Stanley stopped the exercises because it was difficult to do them alone and as he hadn't noticed much improvement in his symptoms there did not seem to be a strong rationale for continuing.

Stanley: "If perhaps my wife would work with me and you had a bit of competition, but I feel such a fool standing on one leg and going up and down on my own and I tends to drop it I do. I'm not very strong disciplined on that, no. I know some people can be so, but not me. I suppose if there was a really good reason I would."

(b) Perceived severity of knee symptoms

The perceived severity of knee symptoms was an important factor in motivation, with those experiencing severe pain and/or loss of mobility being most likely to continue to exercise:

June: "It got worse and worse and I started falling down ... Since I started strengthening these muscles it seems I don't fall over so much which is good ... it's so embarrassing."

The reduction of symptoms was also important in allowing patients to continue to use the tape:

Bridie: "When I did the exercises in the beginning, it wasn't painful with the tape on, so I think that was how I was able to get on with them so well ... whereas if the tape came off and I didn't put it on it was more painful."

The existence of other comorbidites, comparison with others with more limiting disease or a stoic attitude to knee symptoms all seemed to be associated with an attenuation of the motivation to comply:

Beryl: "I see people come in with arthritis and I think oh... god they are in terrible trouble and absolute agony and I think well I've got nothing to complain about."

Geoffrey, who was only partially compliant even during the time he was seeing the physiotherapist, recalled in his interview that he had missed one of the sessions with the physiotherapist because, not unreasonably, he always put the needs of his wife, who had a progressive and debilitating disease, before his own needs: Geoffrey: "There was a time when I missed one [session with the physiotherapist]. I don't know why ...... .I think it was taking the wife somewhere I don't know and I must honestly admit that her needs come as a priority as far as I am concerned."

\section{(c) Ideas about the cause of arthritis}

Ideas about the cause of arthritis also played a part. Those who thought that arthritis was caused by immutable factors such as age, obesity and "wear and tear", tended to have a resigned attitude towards their arthritis. As a consequence they found it hard to believe that the intervention could be effective and this weakened the resolve to comply:

Ethel: "[the exercise and taping]might not help me because I'm getting old but it might help somebody else ... I just think I'm too old really to improve."

As the model (fig 1) suggests, these ideas were sometimes shaped by people's previous experiences of health care:

Geoffrey: "I was having trouble with my knees every so often it did hurt you know with one thing and another. Working in the construction industry there is a lot of lifting and a lot kneeling you see and I felt well I wonder if that's got anything to do with it. So I go to the doctor and all he just simply done was put his hand on my knee, he said "move your leg, ... . you are getting old you've got rheumatism." You see that was it I didn't take any more notice of it [the knee pain] .........

Internalising the notion that there was nothing wrong with his knees contributed to Geoffrey stopping the home exercises:

MT "Since you have stopped seeing [the physiotherapist] have you stopped doing the exercises?"

Geoffrey: "Yes I'm sorry I have yes. But as I said I haven't had no pain . . .. I wondered whether it was temperature or dampness or 
something like that you see. Now there is nothing wrong with them."

MT: "So you feel if there is nothing wrong with it you feel there is not much point in a..."

Geoffrey: "Well that's it. It's the wrong attitude I know."

It may also have contributed to Geoffrey's sense that he did not deserve the physiotherapy intervention:

Geoffrey: "as I told him [one of the doctors running the trial] really I feel a bit guilty taking his time up because there must be a lot of people a lot worse than what I am."

Vi, Hilary, Ethel and Eileen all mentioned their being overweight as contributing to their knee symptoms. Vi gained weight after going through the menopause and had sought help from her GP but didn't receive any. She felt guilty about being overweight but considered any improvement in her knees to be dependent on losing weight:

Vi: "Because when you've got knees like this, you like to do other things, you think I'm gonna go-I'd like to get back to how I was before, but I don't think that's ever going to happen now. I'm sure the weight is the biggest problem . . . . . . I don't eat as much as I use to, nowhere near and I was slim then. But I love me food so."

In contrast, those most likely to be continued compliers tended to believe that although there was no cure for arthritis, there were things they could do to minimise its impact, including the physiotherapy:

June: "I think there is a lot to be learnt and a lot to be done for [arthritis] because even a simple thing like plastering [taping], that is cheap, quick and easy, isn't it?"

(d) The perceived effectiveness of the intervention High levels of continued compliance were closely related to the perception that the physiotherapy intervention was effective. Those who noticed an improvement in their knee symptoms were much more likely to comply than those who did not:

Bridie: "I still do [the exercises] and I remember to stand the correct way without even thinking about it now ....... [The pain] has been a lot better, much better, and I can do things better. Dressing - I don't have to hold on to anything, I can balance now and in fact, you know, I find it a great improvement."

Beryl: "She [the physiotherapist] said the kneecap is out, so she taped it up and pushed it back ... So now if it starts aching, that's what I do. I tape it up and push it back to where it should be."

If, however, the benefits of the physiotherapy were not perceived as sufficient, or there was an allergic reaction to the tape, non-compliance was a rational outcome:

Arthur: I was able to do [the exercises] pretty easily but it didn't appear to me to make a lot of difference ... I carried them on during the time I was taking part in the programme although I've dropped them since.

Vi: "I found that when I didn't have the tape on I missed it. But I don't know whether that was psychological or-but I found it helps because when I was walking down the stairs, it was supporting-you know what I mean? But the only trouble with that was, I found that by
KEY POINTS

- Understood from a patient's perspective decisions to continue or discontinue therapy can be seen to be reasoned and rational.

- Non-compliance is common. Continued compliance depends on a person's perception of their symptoms, the effectiveness of the intervention, their ability to incorporate it into everyday life and support from physiotherapists.

- Therapists should consider using the model of concordance to ensure patients' lay beliefs and social circumstances are explored and understood and that patients are enabled to participate fully in decisions about physical therapy.

- Compliance within RCTs may change over time. This raises the question as to whether we should judge effectiveness according to whether an intervention works when compliance is optimal or taking into account variable levels of compliance.

- The results of RCTs need to be interpreted in the light of qualitative research findings about treatment compliance.

using it quite so often I used to get a reaction [to the sticking plaster] on my knees, it was sore."

\section{Discussion}

Initially, all informants complied with the physiotherapy regimen to some extent, usually citing loyalty to the therapist or an altruistic desire to help in the research. The reasoning underlying compliance in the longer term was more complex. While most understood and acknowledged that they should undertake the exercises and taping often and regularly, many only managed a restricted programme, usually those easiest to accommodate into daily routines or which seemed to convey the most benefit. Some found it difficult to comply at all.

A number of the factors found to contribute to non-compliance with physiotherapy in this study have also been found in sociological research concerned with drug therapies, in particular that symptoms need to be perceived to interfere with life sufficiently to require treatment, and that an intervention needs to be perceived to be effective and to be suitable for incorporation into everyday life. ${ }^{702224}$ This study provides further evidence that patient's decisions to modify or discontinue therapy (physical or drug) are reasoned and rational when examined from the patient's perspective. (see also Donovan and Blake, ${ }^{7}$ Morgan and Watkins, ${ }^{22}$ Conrad $^{33}$ ).

Qualitative methods were used in this study with the primary aim of understanding, from the patient's perspective, what it meant to take part in a physiotherapy programme and then attempt to continue this programme at home. This is, after all, the traditional method of imparting physical therapy advice, and very little is known about what happens to patients subsequently. Interviews were used, because, as 
McCracken notes, these "can take us into the mental world of the individual, to glimpse the categories and logic by which he or she sees the world. It can also take us into the life world of the individual, to see the content and pattern of daily experience." ${ }^{34}$ Nevertheless, it is important to acknowledge that informants may attempt to present themselves to the interviewer as good, proficient members of society. ${ }^{35}$ In this study, for example, informants might have been reluctant to reveal their lack of compliance to avoid appearing lazy or ungrateful for the time that the physiotherapist had spent with them. The interviewer employed in this study was mature and experienced and made it very clear to the informants that she was not involved in the main research project but wished to gain their perspective of the physiotherapy programme. In the event, there seemed little problem with the expression of non-compliance. Indeed, these informants were happy to indicate their initial loyalty to the physiotherapist, and then to admit to their own difficulties with longer term compliance.

This is the first time to our knowledge that a qualitative investigation has been undertaken of compliance with an intervention prospectively within the setting of an RCT. These findings about compliance clearly have relevance for the outcomes of this particular trial. While an awareness that the research was being undertaken because there was uncertainty surrounding the effectiveness of physiotherapy might have been expected to make patients less anxious to comply with the exercise programme, in this study the opposite seems to have been the case. Many informants felt obligated to do the exercises initially because they hoped the knowledge generated by the research could help others like them in the future. Although patients were recruited to the trial from the community, three quarters had previously sought treatment for their knee or other joint problems.

It was very clear that patients were most compliant in the initial period, and so the effectiveness of the physiotherapy intervention would probably have been most apparent at the end of the nine week programme. In this trial, the follow up time was set, a priori, at five months after randomisation, by which time the majority of patients were probably partially compliant at best. In this pragmatic trial, the effect of the physiotherapy was thus diluted by those who were not compliant. ${ }^{27}$ The quantitative results showed a diminution in pain and a significant improvement in muscle strength at five months compared with measurements taken at entry to the trial. This has interesting implications in terms of when the "real" effect of this physiotherapy intervention should have been evaluated: at the time of maximum compliance at nine weeks or at a later time when people have or have not incorporated the intervention into their everyday lives.

The results also have some potential implications for physiotherapy practice. Patients were most compliant when they were still seeing the physiotherapist, and it may be that it is unrealistic for physical interventions to be delivered to patients who are then left without follow up encouragement. Even the most compliant patients indicated that they would have appreciated some further input from the physiotherapist, rather than just being discharged. While the provision of continuing physiotherapy care would require changes in patterns of service delivery, there is increasing recognition of the need to improve rehabilitation services to meet changing patient needs and expectations, and with the British NHS, some encouragement for such developments. ${ }^{36}$

The findings from this study could potentially have implications for evaluations of a wide range of interventions. Randomised controlled trials are now the method of choice for establishing the effectiveness of interventions and if patients do not comply with therapies, then trial outcomes may be affected. ${ }^{89}$ The question remains about what is the most useful outcome: the effectiveness of an intervention when people comply (akin to an explanatory design in which only the "successful" are analysed), or its effectiveness in more general terms taking into account variable compliance (a more pragmatic approach that probably has greater relevance to real life)? Both have relevance to health services: the former in terms of determining whether an intervention such as physiotherapy can work in ideal circumstances; the latter in relation to its effectiveness in everyday life and clinical practice. Perhaps it would not be unreasonable for future trials to include nested qualitative research to allow the re-interpretation of results in relation to levels of non-compliance.

In conclusion, this study and others conducted using qualitative research methods, have shown that non-compliance to physical as well as drug therapies is not only very common, but is usually a reasoned response in relation to a person's perception of their symptoms, their assessment of the effectiveness of the intervention, and their willingness and ability to incorporate the treatment into everyday life. This finding has implications both for the conduct of high quality clinical care as well as the interpretation of trial results. One suggested solution for high quality care is to move away from viewing patients as either compliers or non-compliers with therapy, but to include them as partners in rational decisions about therapy. A working party of the Royal Pharmaceutical Society has recently suggested that doctors and patients should work together to reach decisions about medications-an approach that they call concordance. ${ }^{6}$ Such a change may also be required for physical therapies. In addition, it may well be necessary to conduct more qualitative research nested within RCTs where there is any suggestion that non-compliance might be occurring. Without such changes, the influence of reasoned non-compliance will continue to go unnoticed.

Contributors

$\mathrm{RC}$ and MT initiated the study. ME conducted the interviews. RC supervised the project and undertook the data analysis the accuracy of which was confirmed by JD. PD and BQ devised the trial from which the patients were recruited. RC wrote the first draft of the paper with all authors contributing to the writing of subsequent drafts. RC will act as guarantor. 
Funding: RC is funded by South and West Regional Research Directorate. This qualitative study was funded by a grant from Regional Research Directorate. Conflicts of interest: none.

1 Sackett DL. The magnitude of compliance and noncompliance. In: Sackett DL, Haynes RB, eds. Compliance
with therapeutic regimens. Baltimore: Johns Hopkins Univerwith therapeutic regimens.
sity Press, 1976:9-25.

2 DiMatteo MR. Enhancing patient adherence to medical recommendations. $\mathcal{F} A M A$ 1994;271:79-83.

3 Berg JS, Dischler J, Wagner DJ, et al. Patient compliance. Ann Pharmacother 1993;27:S1-24.

4 Morris LS, Schulz RM. Patient compliance-an overview. $\mathcal{F}$ Clin Pharm Ther 1992;17:283-95.

5 Haynes RB, McKibbon KA, Kanani R. Systematic review of randomised trials of interventions to assist patients to follow prescriptions for medications. Lancet 1996;348:383

6 Royal Pharmaceutical Society of Great Britain. From compliance to concordance achieving adhered goals in medicine taking. Hertfordshire: Merck Sharp \& Dohme, 1997.

7 Donovan JL, Blake DR. Patient non-compliance: deviance or reasoned decision-making? Soc Sci Med 1992;34:507or reasc 13 .

8 Feinstein AR. "Compliance bias" and the interpretation of therapeutic trials. In: Sackett DL, Haynes RB, ed. Compliance with therapeutic regimens. Baltimore: Johns Hopkins

9 Spilker B. Methods of assessing and improving patient compliance in clinical trials. In: Cramer JA, Spilker B, ed. Patient compliance in medical practice and clinical trials. New York: Raven Press, 1991:37-56.

10 Scott DL. Guidelines for the diagnosis, investigation and management of osteoarthritis of the hip and knee. $\mathcal{F} \mathrm{R} \mathrm{Coll}$ Physicians Lond 1993;27:391-6.

11 Hochberg MC, Altman RD, Brandt KD, et al. Guidelines for the medical management of osteoarthritis. Part II. Osteoarthritis of the knee. Arthritis Rheum 1995;38:15416.

12 Puett DW, Griffin MR. Published trials of nonmedicinal and noninvasive therapies for hip and knee osteoarthritis. Ann noninvasive therapies for hip
Intern Med 1994;121:133-40.

13 Balint G, Szebenyi B. Non-pharmacological therapies in osteoarthritis. Baillieres Clin Rheumatol 1997;11:795-815.

14 O'Carroll M, Hendriks O. Factors associated with rheumatoid arthritis patients' compliance with home exercises and splint use. Physiotherapy Practice 1989;5:115-22.

15 Belcon MC, Haynes RB, Tugwell P. A critical review of compliance studies in rheumatoid arthritis. Arthritis Rheum 1984;27:1227-33.

16 Deyo RA. Compliance with therapeutic regimens in arthritis: issues, current status, and a future agenda. Semin Arthritis Rheum 1982;12:233-44.

17 Sluijs EM, Kok GJ, Van der Zee J. Correlates of exercise compliance in physical therapy. Phys Ther 1993;73:771-81.
18 Rejeski WJ, Brawley LR, Ettinger W, et al. Compliance to exercise therapy in older participants with knee osteoarthritis: implications for treating disability. Med $S_{c i}$ Sports Exerc 1997;29:977-85.

19 Donovan JL. Patient decision making. The missing ingredient in compliance research. Int $\mathcal{F}$ Technol Assess Health Care 1995;11:443-55

20 McGavock H, Britten N, Weinman J, ed. A review of the literature on drug adherence. Taking medicines to best effect. London: The Royal Pharmaceutical Society of Great Britain, 1996.

21 Sackett DL, Haynes RB, eds. Compliance with therapeutic regimens. Baltimore: Johns Hopkins University Press, 1976.

22 Morgan M, Watkins CJ. Managing hypertension: beliefs and responses to medication among cultural groups. Sociology of Health and Illness 1988;10:561-78.

23 Gabe J, Bury M. Risking tranquillizer use: cultural and lay dimensions. In: Williams SJ, Calnan M, eds. Modern medicine. Lay perspectives and experiences. London: UCL Press Ltd, 1996:74-9.

24 Britten N. Lay views of drugs and medicines: orthodox and unorthodox accounts. In: Williams SJ, Calnan M, eds. Modern medicine. Lay perspectives and experiences. London: UCL Press Ltd, 1996:48-73.

25 Adams S, Pill R, Jones A. Medication, chronic illness and identity: The perspective of people with asthma. Soc Sci Med 1997;45:189-201.

26 Quilty B, Tucker M, Dieppe P. Patello-femoral joint disease. Disability, quadriceps dysfunction and response to physiotherapy. Final report to NHS National Research and Development Programme, Physical and Complex Disability, 1989. (Available from authors on request).

27 Cushnaghan J, McCarthy C, Dieppe P. Taping the patella medially: A new treatment for osteoarthritis of the knee medially: A new treatment

28 Patton MQ, editor. How to use qualitative methods in evaluation. Newbury Park, CA: Sage, 1987.

29 Hammersley M, Atkinson P, eds. Ethnography. Principles in practice. 2nd ed. London: Routledge, 1995.

30 Burgess RG. The unstructured interview as a conversation. In: Field research: a source book and field manual. London: Routledge, 1982:107-10.

31 Pope C, Zeibland S, Mays M. Analysing qualitative data. BMf 2000;320:114-16.

32 Miles MB, Huberman AM, eds. Oualitative data analysis. 2nd ed. London: Sage, 1994.

33 Conrad P. The meaning of medications: another look at compliance. Soc Sci Med 1985;20:29-37.

34 McCracken G. The long interview. Newbury Park, CA: Sage, 1988

35 Murphy E, Dingwall R, Greatbatch D, et al. Qualitative research methods in health technology assessment: a review of the literature. Health Technol Assess 1998;2.

36 NHS Executive. A directory of developments in occupational therapy, physiotherapy and speech and language therapy services. Leeds: Department of Health, 1998. 